\title{
O lugar e a natureza nas obras de André Severo
}

\author{
Adriane Schrage Wächter \\ DOI 10.20396/eha.vil4.3457
}

Introdução

A presente pesquisa investiga as relações entre a natureza e o lugar a partir das obras do artista sul-riograndense André Severo. Retomando aspectos da natureza na arte e do lugar na geografia que se diferem da paisagem, encontramos elementos de lugares conhecidos, como as praias da região sul, como no Projeto Areal, do qual participou o artista, e de lugares desconhecidos resultantes das apropriações de imagens e manipulações. Experiências que o Areal trouxe em consonância com a prática da errância e intervenções no lugar, semelhantes às que os artistas do movimento da Land Art faziam. Locais com vegetação densa de florestas, outros com natureza ao fundo, e outros com montanhas e neve. A obra acontece pelo encontro com o lugar, desenvolvendo seu processo poético. Em alguns trabalhos de André Severo, a natureza entra em cena criando uma composição com o local em que a ação acontece, como no caso de algumas obras da exposição El Mensajero.

Nas experiências do Projeto Areal, André Severo já vinha experienciando a paisagem através de caminhadas, ações, vídeos, performances. A referência a Robert Smithson acompanhava a jornada dos artistas e aproximava-os da paisagem infinita do Litoral Sul, pois eles compartilhavam o mesmo sentimento de "confinamento" do autor. Dessa forma, essas caminhadas os ajudaram a refletir sobre vários aspectos importantes de seus trabalhos e de sua vida como artistas, antecipando até um novo método de trabalho que seria desenvolvido no Projeto Areal futuramente. A paisagem se constrói através de práticas de errância para alguns artistas, principalmente a partir do século XX.

Suas experiências transformaram o espaço e, consequentemente, a própria paisagem. A partir desse momento, ela estava cada vez mais ligada ao espaço, pois as ações realizadas no local redefiniram as discussões sobre a mesma, já que ela poderia ser vivenciada através de ações, errâncias, percursos, derivas e não apenas representada como antes. Para André, a errância permitiu a observação de lugares nunca experienciados, as praias. Por meio da observação da imensidão e dos trabalhos sobre esse tema, a necessidade de guardar, eternizar, estender o momento, se fez cada vez 
mais latente, culminando na utilização do vídeo. A animação de partes da imagem, entra como um recurso utilizado para se aproximar do que foi visto. O audiovisual é o meio empregado para isto.

\subsection{O Projeto Areal e a errância}

Neste capítulo, esboço considerações acerca da importância do Projeto Areal na trajetória do artista e o conceito de errância, elementos que carregam a ideia de lugar e natureza. O Projeto Areal, ao qual participou o artista continha algumas premissas, como a busca de "sobrevivência" do artista sem depender do sistema, a liberdade criativa por meio da experimentação e a ênfase no processo artístico, sem fins que resultassem em um produto, como, por exemplo, a exposição. Essas experimentações foram importantes principalmente porque foram inovadoras para o campo da arte do Rio Grande do Sul, e revisitaram muitas referências de artista conceituais, por exemplo.

Idealizado por Maria Helena Bernardes e André Severo, esse projeto buscou criar alternativas a uma vida de "artistas de exposição", ou seja, de que maneira eles, como artistas, poderiam relativizar a hegemonia do formato expositivo:

Em 28 de fevereiro de 2000, André Severo e eu demos início a uma nova etapa em nossas trajetórias de artistas a que chamamos Areal. [...] André Severo e eu tomamos a decisão de criar o Areal momento de crise em relação à perspectiva de viver nossas vidas na condição de "artistas de exposição" e que nos levou a empreender uma mudança abrupta de direção; momento marcado por sentimentos conflitivos, entre a urgência de inaugurar uma nova forma de vida na condição de artistas e o temor de mergulhar em um processo que talvez nos levasse ao isolamento e à incomunicabilidade. ${ }^{2}$

O Projeto Areal iniciou com os dois artistas apenas, mas foi expandido mais tarde, sendo uma saída para os artistas desenvolverem e discutirem a questão que permeavam suas práticas no momento, a da "não sobrevivência" do artista fora do sistema da arte contemporânea, porque diferentemente dos anos 1960 e 1970, onde os artistas se expressavam no mundo underground, nesse momento essa opção não existia.

O projeto iniciou com algumas discussões públicas sobre o assunto nos primeiros anos. Dessa forma, os artistas conseguiram desenvolver uma nova forma de produzir arte pensada por eles, compartilhando essas ideias nos debates, não dependendo ao máximo de mediações. Inicialmen-

2 (BERNARDES, 2011, p. 19). 
te, as produções do projeto Areal consistiam nas falas públicas e também em ações, relegando a outro momento a parte escrita das experiências, como comenta Bernardes:

Essa é, também, a primeira vez que incluímos, em uma reflexão escrita, a experiência que inspirou o título desse Documento Areal 10, uma caminhada que André e eu fizemos nas águas do Arroio Dilúvio, em Porto Alegre, no ano de 2002 que, algum tempo depois, recebeu o título de Encontro no Intervalo: Dilúvio e que proporcionou uma profunda tomada de consciência sobre a natureza de nossas ações em Areal, projetando nova luz sobre a reflexão em trânsito que acabou definindo nosso modo de pensar, agir e estar no mundo, como artistas. ${ }^{3}$

Outra importante experiência foi a que resultou no Documento Areal 07, intitulado Histórias de Península e Praia Grande/Arranco, desenvolvida em uma série de deslocamentos pelos areais do Litoral do Sul do Brasil a convite do projeto pedagógico da $7^{\mathrm{a}}$ Bienal de Artes Visuais do Mercosul, do qual a artista comenta:

[...] essa experiência exemplifica, a meu ver, o exercício de uma autonomia amadurecida lentamente ao longo de dez anos, condição que nos permite interagir e colaborar com os mais diferentes parceiros, formas de produção e expressão, seja no campo da arte ou em outros territórios da vida. ${ }^{4}$

Entre 1999 e 2000, André Severo e Maria Helena Bernardes participaram do Programa Rumos Artes Visuais, que foi editado pela primeira vez pelo Instituto Itaú Cultural e que tinha o objetivo de mapear os artistas emergentes de todo o país. Essa experiência propiciou a reinvenção de seus trabalhos longe de exposições e outros eventos culturais com esse objetivo.

A partir daquele 28 de fevereiro de 2000 , nos intervalos entre as viagens pelo Rumos $\mathrm{Vi}$ suais, André Severo e eu nos encontrávamos mensalmente na estação rodoviária de Porto Alegre para tomar o primeiro ônibus em direção ao Litoral Sul de nosso estado, região de campos muito planos e praias vazias. A única regra para essas viagens era que o deslocamento não durasse mais de quatro ou cinco horas, de forma que pudéssemos retornar no mesmo dia, assegurando uma jornada inteira em trânsito. ${ }^{5}$

Nessas jornadas, os artistas caminhavam pelas praias e conversavam sobre o seu futuro como artistas, e sobre alguns artistas da história da arte que já estavam formando uma biblioteca de referências no Areal. A procura por uma forma diferente de apresentação de seus trabalhos era

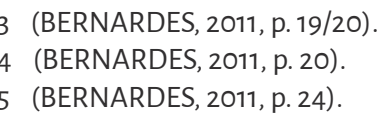


seguidamente manifesta.

O ponto de partida das reflexões sobre arte, sobre como ser artista, sobre o sistema da arte e o próprio trabalho surgem no areal e serão culminantes em toda a trajetória de André Severo. Dessa forma, o artista não separa os desdobramentos que seus trabalhos obtiveram nessa fase até as obras posteriores, que cria uma relação de continuidade. Esse coletivo era importante ao nível nacional, pois pensava a autoria expandida das obras, sendo também uma referência local para o que ela chamava de "artistas de projetos". Os artistas, Maria Helena e André convidaram Elaine e Karin Lambrecht para o projeto areal, pois, elas já executavam trabalhos em salas de exposição e esses projetos que nenhuma instituição financiaria. Então, a ideia do Areal era dar visibilidade para esses trabalhos, como os de sangue, da Karen, que quase ninguém conhecia e a expedição a Mostardas de Elaine Tedesco.

Alguns artistas foram convidados para integrar o projeto areal ao longo do tempo, além de Elaine e Karen, desde que mantivessem essa ligação com o fio condutor, propostas por Maria Helena e André.

Por meio do Areal, André desenvolveu suas deambulações e errâncias, além de ações junto a paisagem, sejam elas, vídeos, performances, fotografias e filmes. Desse modo, a referência a Robert Smithson acompanhava a jornada dos artistas e aproximava-os da paisagem infinita do Litoral Sul, pois eles compartilhavam o mesmo sentimento de "confinamento" do autor. Dessa forma, essas caminhadas os ajudaram a refletir sobre vários aspectos importantes de seus trabalhos e de sua vida como artistas, antecipando até um novo método de trabalho que seria desenvolvido no projeto Areal futuramente, como bem registra a autora:

O espírito dessas errâncias era, ao mesmo tempo, angustiado e liberto: a noção de artista que conhecíamos se desmontava docilmente na paisagem sem espel hos das praias do Sul, em viagens que não eram nem trabalho, nem passeio, nem investigação. $O$ que ignorávamos, àquela altura, é que esses deslocamentos não se resumiriam a um exercício de transição, mas já eram um ponto de chegada; que não nos conduziriam a um novo método de trabalho, mas já conformavam, como diz André Severo, um estado de trabalho. Olhar para o mundo e interagir com ele nesse estado, passou a ser, desde lá, nosso trabalho em Areal. ${ }^{6}$

Juntamente com essas práticas, os debates incitados por esses artistas e por artistas convidados por eles complementavam as ideias sobre o sistema das artes, a maneira de expor e sobre a vida

6 (BERNARDES, 2011, p. 25). 
de artista no sistema contemporâneo. A busca pelas respostas ao ser artista e o sistema das artes motivava-os a experimentar as vivencias pela paisagem, sem uma ideia pré-concebida do que essas experiências se tornariam depois. O encontro com a paisagem e com o outro era fundamental para a experiência, pois possibilitava a troca de vivencias. Essa troca poderia acontecer com apenas uma pessoa, como no caso da cidade de Tavares, conforme relata Maria Helena Bernardes:

Creio que ter vivido essa experiência em diálogo com o Sr. Batista, com os companheiros de viagem que participaram do filme e com a equipe do Projeto Pedagógico, nos permitiu entender que o fundamental é que, como artistas, saibamos compartilhar, da melhor forma possível, o que nos for permitido oferecer. Mesmo que esse compartilhamento seja raro e mínimo, será máximo em intensidade, se tiver o desejo do outro como porta de entrada, como ocorreu em Tavares. ${ }^{7}$

O projeto areal buscava o compartilhamento de experiências, evidenciando a arte como algo ligado a vida, que nascia dela. Ele nasceu por meio de experiências, que não se pretendiam artísticas. Eram simplesmente feitas.

Apesar de André Severo não participar mais do Projeto Areal, as reverberações que essa experiencia trouxeram foram determinantes para seus trabalhos posteriores. O processo artístico do artista é longo e trabalhoso, principalmente no que concerne aos vídeos. Há a manipulação de tempos na imagem, que resultam nas paisagens. São outros modos de construção da paisagem. Sobre o processo experienciado desde o projeto areal até a criação das paisagens, o artista comenta que:

[...] eu sai desse processo ai com muita vontade de não fazer uma exposição, mas de encontrar um lugar onde eu pudesse me enxergar e pudesse enxergar todos esses processos que eu fazia, filme, livro, curadoria [...] durante esses longos processos eu tava 100\% em cada uma das coisas, mas eu não enxergava essa possibilidade de unidade, e ai essa exposição surgiu muito disso [...] foi um momento que a gente propôs, mas a gente nem sabia como ia fazer [...] esses trabalhos não existiam né, e eu ainda tava muito no processo de olhar pras coisas do areal e essa exposição [...] e a Paula chegou num determinado momento do processo que a gente queria fazer isso junto, ai ela me disse assim: eu to percebendo que tu precisa resolver coisas ai, sabe? De outra ordem[...] então vamos fazer o seguinte, ela disse, tá aqui, todos os meus arquivos, todas as minhas coisas, usa isso [...] ve como tujunta essas coisas e a gente vai conversando [...] o que eu fazia tinha a ver com eu ta na frente da câmera ou escrever uma ação para outra possa fazer, ou eu ir pra um lugar filmar paisagens[...] essa coisa de ta nos lugares sempre foram importantes, as ações, os primeiros livros do areal tinham muito a ver com isso de ta nessa paisagem, passar por essa paisagem, viver esses lugares [..] e aqui teve uma coisa assim, que eu acho que começou nesse olhar

7 (BERNARDES, p. 57/58, 2011). 
pras coisas do areal, daqui a pouco eu tava vendo essas paisagens. ${ }^{8}$

Para André, a errância permitiu a observação de lugares nunca antes experenciados, as praias. Por meio da observação da imensidão e dos trabalhos sobre esse tema, a necessidade de guardar, eternizar, estender o momento, se fez cada vez mais latente, culminando na utilização do vídeo. A animação de partes da imagem, entra como um recurso utilizado para se aproximar do que foi visto. $\mathrm{O}$ audiovisual é o meio empregado para isto. $\mathrm{O}$ artista elabora relações entre a errância e a porção nômade que todos nós teríamos, constituída pela vontade de movimentar-se, deslocar-se no sentido de fuga, sair de si na busca de outras referências, desejos internos e outras experiencias.

\subsection{As referências ao movimento artístico da Land Art}

Em meio às várias formas de arte surgindo ou se intensificando nesse momento, artistas contemporâneos voltam-se para as questões da paisagem. Alguns ainda na questão do território, outros em questões sensitivas ou imagéticas, através da fotografia. A partir de então, a paisagem adquire suas formas conforme a preferência e o interesse de cada artista. Ela pode tratar de preocupações ambientais, como no caso da Land Art, que pretende dar ênfase ao local em que a obra foi feita, geralmente mostrando locais deteriorados pelo homem.

Robert Smithson, artista que evidencia a questão da paisagem em terrenos isolados, transformou o lugar. Walter De Maria, artista representante desse movimento, aborda as questões da distância, da medida e da orientação nos trabalhos feitos em lugares isolados. Ele tenta introduzir o tempo como material constituinte do seu trabalho, visando estabelecer relações com o espaço e com o espectador. Pretende evocar no observador a relação de seu lugar no universo, ou seja, levá-lo a refletir sobre seu papel como sujeito no mundo.

André, principalmente no Areal, realizou experiências e reflexões muito próprias apenas de artistas. Tanto a investigação do papel de artista em uma sociedade com um sistema de arte mais consolidado, como as ações na paisagem foram reflexões e práticas importantes. O caminhar e as ações na paisagem foram vivencias significativas tanto para seus trabalhos do momento, quanto os futuros. André já possui um pensamento sobre sua obra que se relaciona com o local, embora não possamos considerar errância no sentido que os artistas modernos a utilizavam.

\footnotetext{
8 (SEVERO, André, 2018).
} 
Embora André não tenha deambulado por regiões desabitadas da cidade como zonas industriais, ele foi ao encontro de lugares próximos a cidades, muitas vezes, para ter a possibilidade de encontro, tanto com o lugar, quanto com as pessoas. Nesse caso, o lugar não importaria tanto quanto na Land Art, pois o mais importante para os artistas é a experiência da troca, que provém do encontro.

Referências bibliográficas

BERNARDES, Maria Helena. Dilúvio. Belo Horizonte:JA.CA, 2011

CARERI, Francesco. Walkscapes: o caminhar como prática estética. São Paulo: Editora G. Cili, 2013

CHIARELLI, Tadeu. Apropriações/coleções. Porto Alegre: Santander Cultural, 2002

CORBIN, Alain. O território do vazio: a praia e o imaginário ocidental. São Paulo: Companhia das Letras, 1989

DEWEY, John. Arte como experiência. São Paulo: Martins Fontes, 2010

REZENDE, Renato; KIFFER, Ana; e BIDENT, Christophe. Experiência e Arte Contemporânea. Rio de Janeiro: Editora Circuito, 2012

SEVERO, André e KRAUSE, Paula. Metáfora. Porto Alegre: Arena, 2015

Consciência errante. São Paulo: Escrituras Editora, 2004 